\title{
XXVIIth ASTIN COLLOQUIUM Copenhagen, Denmark, 1-5 September 1996
}

The 27th ASTIN Colloquium was held at the Moltkes Palæ in the very center of Copenhagen. More than 200 actuaries from 21 countries attended. The colloquium began on Sunday, 1st of September, with a "get-together party" at Assurandørenes Hus. The invited lectures and the working sessions took place on Monday, Wednesday and Thursday. Tuesday was reserved for an all-day excursion to Northern Zealand. The general assembly of ASTIN took place Wednesday afternoon. There CAS announced that Greg Taylor is to receive the Hachemeister price for his article Modelling mortgage insurance claims distribution in the individual life model, ASTIN Bull. Vol. 24, no. 1, 1994. Wednesday evening the Colloquium dinner was served at Restaurant Nimb in Tivoli. After the dinner the participants were invited to watch the traditional Tivoli fireworks. On that particular evening the letters "ASTIN" appeared as a part of the firework display.

The Colloquium was arranged by the Danish Actuarial Association. The members of the organizing committee were Lars Halling, Ulla Plesner, Jan Buschardt and Nikolaj Boysen. The scientific committee was formed by Ole Hesselager, Chresten Dengsøe, Nils Jespersen, Ulla Mønsted and Mette Rytgaard.

The scientific program consisted of three invited lectures and thirty contributed papers. The proceedings, which include all contributed papers, were mailed to the participants prior to the Colloquium. Five speakers had signed up for the Speakers Corner. During the breaks computer packages were presented by C. R. Larsen, S. Bernegger, D. Pfeifer, O. Hesselager, and H. Panjer. In the following I shall give a brief review of the invited and contributed papers.

\section{S.P. Lowe \& J.N. Stanard: An integrated dynamic financial analysis and decision support system for a property catastrophe reinsurer}

The authors presented a model for financial analysis. Both the assets risk and the insurance risk are modelled. In classical portfolio theory the standard deviation of the return is used as risk measure and thereby the Efficient Frontier is found. This approach is generalized by introducing a risk measure that combines assets and liability risk. Different risk measures are discussed, among these the "expected policy holder deficit". The model is currently being used by a property catastrophe insurance company.

\section{N. Keidig, C. Andersen \& P. Fledelius : The Cox regression model for survival data in non-life insurance: Description of claim occurrence and possibilities for experience based individual rating}

The Cox regression model is a standard tool in survival analysis. The model is used for studying the dependence of a hazard rate on both time and covariates. The 
authors apply the model to occurrence of claims in non-life insurance. The hazard rate is the occurrence intensity of an individual policy holder. It is taken to depend on calendar time, and on several covariates such as age, urbanization, and time elapsed since last claim. By an empirical study the authors show that there are dependencies between different covers (policies) on the same individual. If an individual has a high number of claims on one policy then the occurrence rate on his/her other policies will tend to be high too.

\section{A. Kristiansen : On a system of minimum requirements for technical provi- sions in non-life insurance}

In Norway the supervisory authorities have since 1992 stipulated minimum requirements for technical provisions in non-life insurance. Kristiansen presented relatively detailed models used to stipulate both minimum requirements for the overall technical provision, and minimum requirements for the loss provisions. The models allow for fluctuating claim frequencies, and variations in reinsurance structures. In Norway each non-life insurance company must have an actuary appointed by the supervisory authorities. From the audience it was asked whether it is reasonable to postulate minimum provisions, now that each company has its own expert.

\section{Working session : Major hazards}

A. M. Barfod \& D. Lando price derivative contracts (e.g. options) on catastrophe losses. M. Rytgaard discusses in her first article the use of the empirical mean residual lifetime function. In her second article she presents techniques for calculating risk premiums for a certain type of reinsurance cover. Both T. Pentikäinen and Y. Romppainen address problems in credit insurance. Pentikäinen considers specific models, whereas Romppainen studies empirically the impact of booms and recessions in the national economy on credit insurance. J. D. Breen \& E. Kromme consider calculation of stop-loss tariffs by use of simulation.

\section{Working session : Profitability I}

B. Bailleul \& L. Serant apply classification techniques to auto insurance. B. Berliner \& Y.M. Babad present a distribution-free method for constructing bonus-malus system. H. Bühlmann \& A. Gisler reparameterize Hachemeisters regression model, to improve the interpretation. G. Coene \& L. G. Doray present a financially balanced bonus-malus system. R. Kaas, D. Dannenburg \& M. Goovaerts generalize Jewells theorem on exact credibility from the Bühlmann model to the Bühlmann-Straub model. W. Neuhaus finds optimal Bayes estimators under linear constraints. J. Pinquet presents a bonus-malus system that accounts for the cost of claims. D. Skurnick \& M. Grandisson consider multi-line risk measurement. Their model and aims are closely related to those of Lowe \& Stanard. J. Spreeuw discusses the issue of solidarity in group life insurance. 


\section{Working session : Solvency}

B. Ajne discusses how to set aside solvency margin relatively to technical reserves and relatively to premium income. D. C.M. Dickson \& A. D. Egídio dos Reis allow, in the classical surplus process, the insurer to borrow money in case of negative surplus. S. Haastrup and E. Arjas present a Bayesian model for continuous time claims reserving. E. Kremer applies threshold autoregressive models to claims reserving. C.R. Larsen approximates the distribution of a predictor (claim reserve) using Bootstrap methods. The approach does not depend on the reserving method used. F. Larsen, S. Monty \& C. Clemmensen construct a dynamic loss reserving model. The model is a day by day model, and it allows for dynamic changes in both occurrences and reporting of claims. J. Paulsen and H.K. Gjessing find the ruin probability for a risk process with stochastic interest rate and stochastic inflation. B.L. Sandqvist presents an empirical non-parametric approach to prediction of reported but not settled claims. The work of Sandqvist is related to that of C.R. Larsen since they both work under a minimal set of assumptions.

\section{Working session : Profitability II}

P. De Angelis \& N. Ettore D'Ortona discuss optimal reinsurance structures. A. Deis presents results from an analysis of permanent disability for a Danish population of impaired lives. J. Dhaene, G. Willmot \& B. Sundt derive recursions for distribution functions and stop-loss transforms. C. Hipp illustrates how to calculate total claims distributions by use of a spreadsheet. W. Hürlimann contributes with eight papers. He treats tail cutting methods, recursive methods, mean scaled compound distributions, mean scaled individual risk models, bounds for expected financial payoffs, loss variance bounds, and stop-loss bounds for diatomic bivariate sums. J.P. Nielsen \& P. Voldsgaard apply marker dependent hazard estimation to health dependent mortality. The methods used are related to the Cox regression model used by Keiding, Andersen \& Fledelius. G. Taylor constructs a loss reserving model that treats the individual layers of an excess of loss reinsurance.

\section{Working session : Speaker's corner}

S. Wang implements proportional hazard transforms in rate making. A. Gisler considers the interaction between tariff-structure and bonus-malus. H. Schmitter asked for help to estimate change points in a tariff. Paul Johansen gave a talk with the title "mathematics v.s. statistics". He urged young actuaries to develop models for individual non-life policies. Gunnar Benktander gave an overview of the history of ASTIN. Gunnar ended his talk by citing Paul Johansens characterization of the difference between life- and non-life insurance: "you can only die once".

The 28th ASTIN Colloquium will take place 10-13 August 1997 in Cairns, Australia.

Svend HaAstrup, Copenhagen 